\title{
REPLY COMMENT
}

\section{Most scleractinian corals and octocorals host a single symbiotic zooxanthella clade}

\author{
Tamar L. Goulet* \\ Department of Biology, University of Mississippi, University, Mississippi 38677, USA
}

\begin{abstract}
The possibility that scleractinian corals and octocorals could change their symbiotic zooxanthellae in response to global warming is alluring. In Goulet (2006; Mar Ecol Prog Ser 321:1-7) I concluded that corals capable of hosting multiple zooxanthella (Symbiodinium) clades may change zooxanthellae, while those hosting one clade may not. Since the majority of corals (77\%) host a single Symbiodinium clade, their survival will depend on whether or not the existing symbioses withstand the changing environment. Baker \& Romanski (2007; Mar Ecol Prog Ser 335:237-242, this volume) question whether these conclusions apply to scleractinian corals. They subscribe to the null hypothesis that most corals host multiple clades and argue that if sampling does not reveal multiple clades in a coral species, this is due to insufficient sample sizes, sampling sites and/or detection techniques. In this Reply Comment, I demonstrate that sample sizes are adequate: of the scleractinian corals capable of hosting multiple clades, $87.5 \%$ have been detected with sample sizes $\leq 5$, and $97.7 \%$ with sample sizes $\leq 10$. Within scleractinian coral families only a minority $(29 \%)$ of species host multiple clades, concurring with the overall finding at the species level. The conclusions in Goulet (2006) are valid, and the message that coral reefs may undergo a reduction in biodiversity should be heeded.
\end{abstract}

KEY WORDS: Zooxanthella · Symbiodinium • Coral · Bleaching · Global warming · Symbiosis · Adaptive bleaching hypothesis

Stony (scleractinian) corals and octocorals (collectively referred to as 'corals') may deal with changing environments by altering the host-symbiont (coralzooxanthella) genotypic combination. In Goulet (2006), I proposed that the ability to change symbionts and the ability to host multiple zooxanthella (Symbiodinium) clades are intertwined. Since most coral species host a single clade, I concluded that most coral species may not change their symbionts. In their Comment on Goulet (2006), Baker \& Romanski (2007, this volume) question my claims. The debate between Baker \& Romanski and myself stems from our opposing null hypotheses.

Baker \& Romanski (2007) subscribe to the null hypothesis that a coral species hosts multiple zooxanthella clades (Baker 2003). This null hypothesis is flawed, since it cannot be refuted: if, for a given coral species, multiple clades are not found, then one can argue that this is due to insufficient sample sizes, sampling sites and/or detection methods, and Baker \& Romanski (2007) use these arguments to explain why so few species host multiple clades.

An opposing null hypothesis states that a coral species hosts a single zooxanthella clade. This null hypothesis can be confirmed or refuted, e.g. if multiple clades are discovered in a given coral species, either within a colony or between colonies at any depth or geographic location. I am a proponent of the latter null hypothesis.

In Goulet (2006), I stated that $77 \%$ of coral species host only 1 zooxanthella clade. My findings are supported by previous studies. Baker (2003), with a dataset of 107 scleractinian coral species, found that $64 \%$ hosted a single clade. LaJeunesse (2002) found that $72 \%$ of cnidarians off Yucatan and $92 \%$ of cnidarians 
in the Bahamas hosted a single clade, and a single type within a clade. Even Baker \& Romanski (2007; their Table 1, Row 2) find a similar percentage (75\%) of corals hosting a single clade when they analyze their entire dataset (without excluding any of their data). Since Baker \& Romanski's null hypothesis that coral species host multiple clades is neither supported by the cited studies (LaJeunesse 2002, Baker 2003, Goulet 2006), nor by their own data, they dismiss large parts of the dataset. Baker \& Romanski (2007) raise the points of sample size, within-clade variability and 'cryptic Symbiodinium' to rationalize why they ignore the current findings. The current data cannot be dismissed, and the conclusions in Goulet (2006) are valid.

\section{Sample size of the Goulet (2006) dataset is 31\% larger than the Baker \& Romanski (2007) dataset}

The datasets in Goulet (2006) and Baker \& Romanski (2007) overlap, but they are not identical. Although Baker \& Romanski (2007) are concerned with withinspecies sample sizes, they dismiss $31 \%$ of the Goulet (2006) dataset. Baker \& Romanski (2007, p. 237) state that they excluded:

(1) Species reported only to the generic level ('sp.' or 'spp.'): In Goulet (2006), I incorporated reports to the genus level (sp.). For example, if 3 studies reported Acropora sp. as hosting Clade $\mathrm{C}$ zooxanthellae, and 1 report stated that Acropora sp. hosted Clade A, I entered in the dataset that Acropora spp. hosted multiple clades (A and C). This is a conservative approach, since if each Acropora sp. were a different species, I would have listed 4 species hosting a single clade instead of 1 species hosting multiple clades. This approach potentially inflated the number of corals hosting multiple clades. Within my dataset, 21 unknown species (spp.) of scleractinian corals are categorized as hosting multiple clades while 17 unknown species host a single clade. These data add nearly the same number to each category and do not affect the overall conclusions. Furthermore, Baker et al.'s (2004) general statement that 'shifting to new algal symbionts may safeguard devastated reefs from extinction' relies solely on data at the generic level.

(2) Unpublished data: Baker \& Romanski (2007) do not include T. L. Goulet et al. (unpubl.; data available upon request) in their dataset, which repre- sents a small fraction (5.4\%) of the Goulet dataset; conversely, they use other unpublished data to substantiate their claims.

\section{Within coral species sample sizes are sufficient}

Baker \& Romanski (2007) question whether withinspecies sample sizes are adequate. Because the majority of octocorals (regardless of sample size) host a single Symbiodinium clade, Baker \& Romanski (2007) set them aside and focus on raising doubts about the current data on Symbiodinium clades in scleractinian coral species. They allege that: 'As sampling effort per species increases, the number of Symbiodinium clades documented also increases' (p. 238). This claim is incorrect. If a coral species, capable of hosting multiple Symbiodinium clades, were sampled 150 times, it does not mean that it took 150 samples to uncover the fact that it can host multiple clades. In regard to sample size, the critical question is: what is the minimum sample size that would detect that a coral species hosts multiple clades? Once a coral species is categorized as hosting multiple clades, further increasing the sample size does not change that categorization.

By re-analyzing the data, I determined the minimum sample size that revealed multiple clades in scleractinian coral species (Fig. 1). Although octocorals are a major

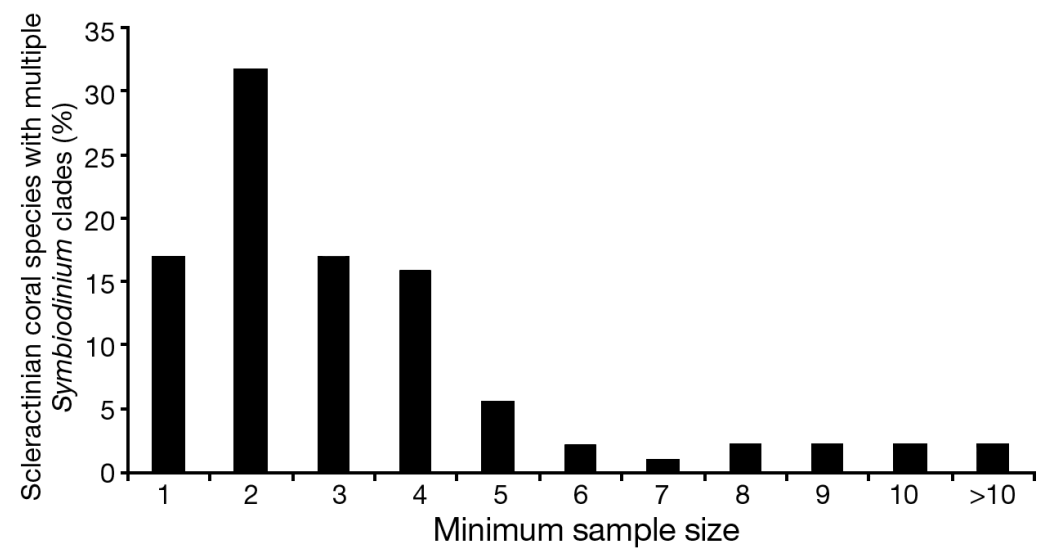

Fig. 1. Minimum sample size that detected multiple Symbiodinium clades in scleractinian coral species. Bars are percent (\%) of scleractinian coral species $(\mathrm{n}=88)$. Only scleractinian corals identified to the species level were included in the analysis. Colpophyllia natans, for example, hosts Clades B, C and D (Baker \& Rowan 1997, Baker 1999, 2001, LaJeunesse 2002, Banaszak et al. 2006). On one reef, the only sample collected had Clades B and C (LaJeunesse 2002); hence, the minimum sample size was 1. Acropora horrida's minimum sample size was 4, based on 3 colonies hosting Clade A and one hosting Clade C (Baker 1999, Fabricius et al. 2004). If a report on a given coral species did not specify the sampling effort with regard to depths or reefs, it was not possible to determine whether the second clade was detected in the second sample, or in the last; a conservative approach was adopted, listing the total number of colonies sampled as the minimum number. For example, Euphyllia paraancora (Chen et al. 2005b) was listed as hosting multiple zooxanthella clades with a minimum sample size of 20 
constituent of coral reefs, in order to address Baker \& Romanski's (2007) claims, I focused on scleractinian corals identified to the species level. Two examples, representative of the dataset, illustrate the findings. The categorization of Acropora brueggemanni as hosting multiple clades is based on 2 colonies (Fabricius et al. 2004). At the other end of the spectrum, Montastrea faveolata has been sampled at least 275 times (Rowan \& Knowlton 1995, Rowan et al. 1997, Baker 1999, Toller et al. 2001, LaJeunesse 2002, Banaszak et al. 2006, Thornhill et al. 2006, Warner et al. 2006), and multiple clades were documented in every study. For example, all of 46 colonies in Panama contained multiple clades (Rowan et al. 1997), and in 2 colonies sampled off Yucatan, 1 hosted Clade D and 1 hosted Clade $\mathrm{C}$ zooxanthellae (LaJeunesse 2002), demonstrating that, conservatively, a minimum sample size of 2 revealed that $M$. faveolata hosts multiple clades.

Of the 88 scleractinian coral species known to host multiple clades, $87.5 \%$ were detected as hosting multiple clades with a minimum sample size of 5 colonies or less; a further $10.2 \%$ of the scleractinian coral species were detected as hosting multiple clades with sample sizes from 6 to 10 (Fig. 1). Thus, $97.7 \%$ of all scleractinian corals hosting multiple clades were found to do so on the basis of $\leq 10$ samples (Fig. 1). Baker et al. (2004; their online supplementary information) also detected multiple clades in 13 scleractinian genera with low sample sizes ( 3 genera with $n=1 ; 6$ genera with $n=2$; 2 genera each with $\mathrm{n}=3$ and $\mathrm{n}=5$ ).

Baker \& Romanski's (2007) claim that increasing sampling effort will reveal more clades is based on a sampling artifact. Baker \& Romanski (2007) provide the reason for this artifact, stating that, 'more flexible coral species also tend to have attracted more sampling effort' (p. 238). They have also attracted more public attention; a case in point: since the description that some coral species host multiple clades (Rowan \& Knowlton 1995), all articles published in Science and Nature involving zooxanthella cladal identity focused on coral species that can host multiple clades (Rowan et al. 1997, Baker 2001, Baker et al. 2004, Lewis \& Coffroth 2004, Little et al. 2004, Rowan 2004). Because of the extensive sampling of scleractinian corals hosting multiple clades, these species comprise a minimum of $64 \%$ of the scleractinian corals in the category of extensively sampled species (Baker \& Romanski 2007, their Table 1, Row 7). Consequently, they are overrepresented in the 3 bars representing sample sizes $>10$ in Fig. 1c of Baker \& Romanski (2007), generating the false impression that a correlation exists between large sample sizes and multiple clades. Given that $97.7 \%$ of scleractinian corals hosting multiple clades are detected with small sample sizes, the conclusions reached in Goulet (2006) remain valid.

\section{The majority of coral species within a scleractinian coral family host a single zooxanthella clade}

Baker \& Romanski (2007, their Table 2) present data at the family level to support their claim that the hosting of multiple clades is prevalent in scleractinian corals. They list the number of species sampled in each family without mentioning how many of those species

Table 1. Percent of coral species within a scleractinian coral family that host multiple Symbiodinium clades. Table modified from Baker \& Romanski (2007) (B\&R); bold: additional data. Only scleractinian corals identified to the species level were included in the analysis

\begin{tabular}{|c|c|c|c|c|c|c|c|c|c|c|c|c|}
\hline Family & $\mathrm{A}$ & B & $\mathrm{C}$ & $\begin{array}{c}\text { Clade }- \\
\text { D }\end{array}$ & $\mathbf{E}$ & $\mathrm{F}$ & $\bar{G}$ & $\begin{array}{c}\text { Species } \\
\text { with } \\
\text { multiple } \\
\text { clades (\%) }\end{array}$ & $\begin{array}{c}\text { No. of } \\
\text { species } \\
\text { sampled }\end{array}$ & $\begin{array}{c}\text { No. of } \\
\text { species } \\
\text { sampled } \\
\text { in B\&R }\end{array}$ & $\begin{array}{c}\text { No. of } \\
\text { samples } \\
\text { in B\&R } \\
\text { (median) }\end{array}$ & $\begin{array}{c}\text { No. of } \\
\text { samples } \\
\text { (median) }\end{array}$ \\
\hline Acroporidae & $\times$ & $x$ & $x$ & $x$ & $x$ & & & 22 & 91 & 65 & 5 & 4 \\
\hline Agariciidae & $x$ & $x$ & $x$ & $x$ & & & & 21 & 28 & 24 & 3.5 & 5 \\
\hline Astrocoeniidae & $\times$ & $\times$ & $x$ & $\times$ & & & & 33 & 9 & 8 & 5.5 & 14 \\
\hline Dendrophylliidae & $\times$ & & $x$ & $\times$ & & & & 33 & 6 & 5 & 2 & 3 \\
\hline Euphylliidae & & & $x$ & $x$ & & & & 33 & 6 & 5 & 5 & 4 \\
\hline Faviidae & $x$ & $x$ & $x$ & $x$ & & & & 42 & 62 & 52 & 3 & 3 \\
\hline Fungiidae & $\times$ & & $x$ & $x$ & & & & 21 & 19 & 12 & 2 & 2 \\
\hline Meandrinidae & $\times$ & $x$ & $x$ & & & & & 75 & 4 & 4 & 2.5 & 4.5 \\
\hline Merulinidae & & & $x$ & $\times$ & & & & 29 & 7 & 7 & 4 & 7 \\
\hline Mussidae & & $x$ & $x$ & $\times$ & & & & 17 & 18 & 11 & 2 & 2 \\
\hline Oculinidae & & $x$ & $x$ & $x$ & & & & 20 & 5 & 4 & 8 & 6 \\
\hline Pectiniidae & & & $x$ & $x$ & & & & 20 & 10 & 6 & 2 & 2 \\
\hline Pocilloporidae & $\times$ & & $\times$ & $\times$ & & & $x$ & 64 & 11 & 10 & 9.5 & 15 \\
\hline Poritidae & $\times$ & $\times$ & $x$ & $\times$ & & $x$ & & 23 & 31 & 25 & 6 & 7 \\
\hline Rhizangiidae & & $\times$ & & & & & & $\mathbf{0}$ & 1 & 1 & 11 & 12 \\
\hline Siderastreidae & $x$ & $\times$ & $x$ & $x$ & & & & 15 & 13 & 11 & 5 & 6 \\
\hline
\end{tabular}


actually host multiple clades. I have modified their table to include the percentage of species that host multiple clades within each family (Table 1). These data demonstrate that, on average, scleractinian corals hosting multiple clades comprise only $29 \%$ of the species within a family (Table 1).

Discussion of the phylogeny of hosting multiple clades, and of the reasons why in some families more species host multiple clades, is outside the scope of a debate over Goulet (2006). The data, however, illustrate that within most coral families, including dominant reef building taxa, species hosting multiple clades are not the norm. Baker \& Romanski's (2007) statement 'In the example of Acropora, we predict that, as more data are collected, it will become apparent that the genus (comprising 120 species) is flexible to a much greater degree than the sparse dataset currently indicates' (p. 239) is speculation; data already exist for 91 Acropora species ( $3 / 4$ of the species) of which only $22 \%$ host multiple clades (Table 1 ).

\section{New publications have not altered the interpretation of the data}

Baker \& Romanski (2007) mention 18 publications, dating from before and after Goulet (2006), stating that they are critical to the meta-analysis. Of these, 4 references (LaJeunesse et al. 2004, van Oppen 2004, Chen et al. 2005a, van Oppen et al. 2005) were actually included in the Goulet (2006) dataset, but inadvertently omitted from the references, and Berkelmans \& van Oppen (2006) was cited. The inclusion of these studies explains some of the discrepancy in the species numbers between my dataset and that of Baker \& Romanski (2007).

The remaining papers contributed only 3 new coral species to the dataset, all hosting a single clade (Huang et al. 2006, Pochon et al. 2006, Warner et al. 2006). The additional references increase sample sizes, and, in some instances, add new geographic locations to the dataset, but they do not change the category of any of the coral species (i.e. from single to multiple clade hosts). Additional papers on zooxanthella genotypes are continuously being published (Barbrook et al. 2006, LaJeunesse et al. 2007), but they also do not change the conclusions reached in Goulet (2006). I have added all relevant new data to the analyses in Fig. 1 and Table 1.

\section{Within-cladal variability exists, but does not equate to flexibility}

Using different molecular techniques, one can address questions about zooxanthellae at multiple levels (van Oppen \& Gates 2006). Corals hosting a single algal clade do display within-cladal variability, as one would expect at the population or individual level. Intra-cladal variability, however, does not equate to flexibility. In the octocoral Plexaura kuna, for example, every coral genotype hosts a unique zooxanthella genotype, demonstrating enormous variability at the individual coral level (Goulet \& Coffroth 2003a,b). The unique zooxanthella genotype within a coral, however, does not change over time, or upon transplantation to novel environments (Goulet \& Coffroth 2003b). To date, there has been no indication that corals hosting a single zooxanthella clade change that clade or even a type within that clade.

\section{Corals hosting one clade have not been documented to change symbionts}

Most studies on zooxanthella clades have focused on identifying which clade(s) are found in a coral species in nature. In Goulet (2006, Table 2) I listed the few examples-among corals hosting one cladewhere molecular techniques provided within-clade resolution, and the genetic identity of the zooxanthellae was followed over time or documented under experimentally manipulated conditions. My conclusion, that cladal fidelity exists in corals hosting one clade, however, is based not just on those few studies. As opposed to the absence of change in coral species hosting a single clade, in every single instance in which cladal turnover was documented, it occurred in a coral species known to host multiple clades (Baker 2001, Baker et al. 2004, Chen et al. 2005a, Berkelmans \& van Oppen 2006, Thornhill et al. 2006). Consequently, although few experimental studies exist, for both corals hosting single and multiple clades, taken together, genotypic turnover in zooxanthellae has occurred only in coral species capable of hosting multiple clades; no turnover has been reported from corals hosting a single clade.

This pattern, observed from manipulative and temporal experiments, is supported by survey data. Corals hosting a single clade maintain that same clade at different depths (Diekmann et al. 2002, Goulet \& Coffroth 2003a, 2004, Iglesias-Prieto et al. 2004), on different reefs within an area (van Oppen et al. 2001, Goulet \& Coffroth 2003b, 2004, Fabricius et al. 2004, Chen et al. 2005b, Visram \& Douglas 2006), and in different geographic locations (LaJeunesse 2002, Chen et al. 2003, Goulet \& Coffroth 2004, Karako-Lampert et al. 2004, LaJeunesse et al. 2004, van Oppen 2004). The conclusion that coral species hosting one clade do not change that clade is therefore based on multiple lines of evidence. On the other hand, Baker \& Romanski's (2007) 
argument that the findings on corals hosting multiple clades likely apply to most scleractinian coral species is hypothetical and not supported by the current data.

\section{Detecting 'cryptic zooxanthellae' does not prove that these zooxanthellae are in symbiosis}

In Goulet (2006), I discussed the phenomenon of uncovering zooxanthella genotypes not documented from a coral species in nature ('cryptic zooxanthellae') by culturing or by using molecular techniques. In corals capable of hosting multiple clades, finding cryptic zooxanthellae is not surprising and fits with the suggestion that these species are 'shuffling' between existing symbionts based on external conditions (Buddemeier \& Fautin 1993, Baker 2003, Berkelmans \& van Oppen 2006). For coral species hosting a single clade, I referred to 2 explanations from the literature about cryptic zooxanthellae. The first possibility is that the cryptic zooxanthellae were an artifact of a molecular technique. Baker \& Romanski (2007) point out that cryptic zooxanthellae may not be an artifact (Apprill \& Gates 2007). To further their argument, Baker \& Romanski (2007) refer to J. C. Mieog et al. (unpubl.), stating that Acropora tenuis adults host one clade. Since $A$. tenuis adults actually host multiple zooxanthella clades (LaJeunesse et al. 2004), detecting multiple clades (cryptic or not) in A. tenuis is not surprising and does not change the conclusions reached in Goulet (2006).

Baker \& Romanski (2007), however, ignore the second explanation presented in Goulet (2006). Detecting cryptic zooxanthellae from a host sample does not demonstrate that these genotypes are in symbiosis with the host. Corals produce mucus, which can trap particles (either alive or dead) on their external surfaces (reviewed in Brown \& Bythell 2005). Cryptic zooxanthellae might be surface contaminants (Santos et al. 2001, Baker 2003). Corals are also an open system. Corals ingest, among other things, zooplankton, pinnate diatoms, ciliates, bacteria, cyanobacteria and flagellates, including dinoflagellates (Ribes et al. 1998, Houlbreque et al. 2004). Since Symbiodinium spp. are dinoflagellates, some may be ingested. To date, there is no proof of a symbiotic association between cryptic zooxanthellae and adult colonies in coral species hosting a single Symbiodinium clade.

\section{Conclusions}

The data available today do not agree with Baker \& Romanski's (2007) null hypothesis that corals host multiple zooxanthella clades. They focus on a subset of the data, citing limited sample sizes, sampling sites, and/or detection techniques as reasons to disregard most of the current data. This approach demonstrates their belief in a non-refutable null hypothesis, since one can never sample all parts of all colonies, and all corals, at all depths, at all sites, 365 days a year, with molecular techniques that may be described in the future.

The current data demonstrate that most corals $(77 \%)$ host a single zooxanthella clade. The null hypothesis that a coral species hosts a single clade can be confirmed or refuted at any time. The average percentage of coral species hosting a single clade is uncannily similar when it is calculated by different researchers on different datasets or when it is generated using the coral species or family level. Corals that host a single zooxanthella clade have not been documented to change that clade or genotypes within that clade. Only a minority of coral species hosts multiple clades. Consequently, generalizations for the entire coral reef should not be made based on coral species capable of hosting multiple clades. Proclamations that corals may adapt with thermally more tolerant symbionts and thereby survive global climate change should be stated with the caveat that only $23 \%$ of coral species may be able to do so.

Acknowledgements. I thank R. Buchholz, D. Goulet, C. Johnson, and U. Liberman for their insightful comments on this article. I thank A. Baker and A. Romanski, and O. Kinne and $\mathrm{H}$. Browman for the scientific discussion. This article is dedicated to the memory of L. Muscatine.

\section{LITERATURE CITED}

Apprill AM, Gates RD (2007) Recognizing diversity in coral symbiotic dinoflagellate communities. Mol Ecol 16: $1127-1134$

Baker AC (1999) The symbiosis ecology of reef-building corals. PhD dissertation, University of Miami, Miami, FL

Baker AC (2001) Reef corals bleach to survive change. Nature 411:765-766

Baker AC (2003) Flexibility and specificity in coral-algal symbiosis: diversity, ecology, and biogeography of Symbiodinium. Annu Rev Ecol Syst 34:661-689

Baker AC, Romanski AM (2007) Multiple symbiotic partnerships are common in scleractinian corals, but not in octocorals: Comment on Goulet (2006). Mar Ecol Prog Ser 335: $237-242$

Baker AC, Rowan R (1997) Diversity of symbiotic dinoflagellates (zooxanthellae) in scleractinian corals of the Caribbean and Eastern Pacific. Proc 8th Int Coral Reef Symp, Panama 2:1301-1306

Baker AC, Starger CJ, McClanahan TR, Glynn PW (2004) Corals' adaptive response to climate change. Nature 430: 741

Banaszak AT, Barba Santos MG, LaJeunesse TC, Lesser MP (2006) The distribution of mycosporine-like amino acids (MAAs) and the phylogenetic identity of symbiotic dinoflagellates in cnidarian hosts from the Mexican Caribbean. J Exp Mar Biol Ecol 337:131-146

Barbrook AC, Visram S, Douglas AE, Howe CJ (2006) Mol- 
ecular diversity of dinoflagellate symbionts of cnidaria: the psbA minicircle of Symbiodinium. Protist 157:159-171

Berkelmans R, van Oppen MJH (2006) The role of zooxanthellae in the thermal tolerance of corals: a 'nugget of hope' for coral reefs in an era of climate change. Proc R Soc Lond Ser B 273:2305-2312

Brown BE, Bythell JC (2005) Perspectives on mucus secretion in reef corals. Mar Ecol Prog Ser 296:291-309

Buddemeier RW, Fautin DG (1993) Coral bleaching as an adaptive mechanism - a testable hypothesis. BioScience 43:320-326

Chen CA, Lam KK, Nakano Y, Tsai WS (2003) A stable association of the stress-tolerant zooxanthellae, Symbiodinium clade D, with the low-temperature-tolerant coral, Oulastrea crispata (Scleractinia: Faviidae) in subtropical nonreefal coral communities. Zool Stud 42:540-550

Chen CA, Wang JT, Fang LS, Yang YW (2005a) Fluctuating algal symbiont communities in Acropora palifera (Scleractinia: Acroporidae) from Taiwan. Mar Ecol Prog Ser 295: 113-121

Chen CA, Yang YW, Wei NV, Tsai WS, Fang LS (2005b) Symbiont diversity in scleractinian corals from tropical reefs and subtropical non-reef communities in Taiwan. Coral Reefs 24:11-22

Diekmann OE, Bak RPM, Tonk L, Stam WT, Olsen JL (2002) No habitat correlation of zooxanthellae in the coral genus Madracis on a Curaçao reef. Mar Ecol Prog Ser 227: 221-232

Fabricius KE, Mieog JC, Colin PL, Idip D, van Oppen MJH (2004) Identity and diversity of coral endosymbionts (zooxanthellae) from three Palauan reefs with contrasting bleaching, temperature and shading histories. Mol Ecol 13:2445-2458

Goulet TL (2006) Most corals may not change their symbionts. Mar Ecol Prog Ser 321:1-7

Goulet TL, Coffroth MA (2003a) Genetic composition of zooxanthellae between and within colonies of the octocoral Plexaura kuna, based on small subunit rDNA and multilocus DNA fingerprinting. Mar Biol 142:233-239

Goulet TL, Coffroth MA (2003b) Stability of an octocoral-algal symbiosis over time and space. Mar Ecol Prog Ser 250: $117-124$

Goulet TL, Coffroth MA (2004) The genetic identity of dinoflagellate symbionts in Caribbean octocorals. Coral Reefs 23:465-472

Houlbreque F, Tambutte E, Allemand D, Ferrier-Pages C (2004) Interactions between zooplankton feeding, photosynthesis and skeletal growth in the scleractinian coral Stylophora pistillata. J Exp Biol 207:1461-1469

Huang H, Dong ZJ, Huang LM, Zhang JB (2006) Restriction fragment length polymorphism analysis of large subunit rDNA of symbiotic dinoflagellates from scleractinian corals in the Zhubi Coral Reef of the Nansha Islands. J Integr Plant Biol 48:148-152

Iglesias-Prieto R, Beltran VH, LaJeunesse TC, Reyes-Bonilla $H$, Thome PE (2004) Different algal symbionts explain the vertical distribution of dominant reef corals in the eastern Pacific. Proc R Soc Lond Ser B 271:1757-1763

Karako-Lampert S, Katcoff DJ, Achituv Y, Dubinsky Z, Stambler N (2004) Do clades of symbiotic dinoflagellates in scleractinan corals of the Gulf of Eilat (Red Sea) differ from those of other coral reefs? J Exp Mar Biol Ecol 311:301-314

LaJeunesse TC (2002) Diversity and community structure of symbiotic dinoflagellates from Caribbean coral reefs. Mar Biol 141:387-400

Editorial responsibility: Howard Browman (Associate Editorin-Chief), Storebø, Norway
LaJeunesse TC, Bhagooli R, Hidaka M, DeVantier L, Done T, Schmidt GW, Fitt WK, Hoegh-Guldberg O (2004) Closely related Symbiodinium spp. differ in relative dominance in coral reef host communities across environmental, latitudinal and biogeographic gradients. Mar Ecol Prog Ser 284:147-161

LaJeunesse TC, Reyes-Bonilla H, Warner ME (2007) Spring 'bleaching' among Pocillopora in the Sea of Cortez, Eastern Pacific. Coral Reefs doi10.1007/s00338-006-0189-3

Lewis CL, Coffroth MA (2004) The acquisition of exogenous algal symbionts by an octocoral after bleaching. Science 304:1490-1492

Little AF, van Oppen MJH, Willis BL (2004) Flexibility in algal endosymbioses shapes growth in reef corals. Science 304 : 1492-1494

Pochon X, Montoya-Burgos JI, Stadelmann B, Pawlowski J (2006) Molecular phylogeny, evolutionary rates, and divergence timing of the symbiotic dinoflagellate genus Symbiodinium. Mol Phylogenet Evol 38:20-30

Ribes M, Coma R, Gili JM (1998) Heterotrophic feeding by gorgonian corals with symbiotic zooxanthella. Limnol Oceanogr 43:1170-1179

Rowan R (2004) Coral bleaching: thermal adaptation in reef coral symbionts. Nature 430:742

Rowan R, Knowlton N (1995) Intraspecific diversity and ecological zonation in coral-algal symbiosis. Proc Natl Acad Sci USA 92:2850-2853

Rowan R, Knowlton N, Baker A, Jara J (1997) Landscape ecology of algal symbionts creates variation in episodes of coral bleaching. Nature 388:265-269

Santos SR, Taylor DJ, Coffroth MA (2001) Genetic comparisons of freshly isolated versus cultured symbiotic dinoflagellates: implications for extrapolating to the intact symbiosis. J Phycol 37:900-912

Thornhill D, LaJeunesse T, Kemp D, Fitt W, Schmidt G (2006) Multi-year, seasonal genotypic surveys of coral-algal symbioses reveal prevalent stability or post-bleaching reversion. Mar Biol 148:711-722

Toller WW, Rowan R, Knowlton N (2001) Zooxanthellae of the Montastraea annularis species complex: patterns of distribution of four taxa of Symbiodinium on different reefs and across depths. Biol Bull 201:348-359

van Oppen MJH (2004) Mode of zooxanthella transmission does not affect zooxanthella diversity in acroporid corals. Mar Biol 144:1-7

van Oppen MJH, Gates RD (2006) Conservation genetics and the resilience of reef-building corals. Mol Ecol 15: 3863-3883

van Oppen MJH, Palstra FP, Piquet AMT, Miller DJ (2001) Patterns of coral-dinoflagellate associations in Acropora: significance of local availability and physiology of Symbiodinium strains and host-symbiont selectivity. Proc R Soc Lond Ser B 268:1759-1767

van Oppen MJH, Mieog JC, Sánchez CA, Fabricius KE (2005) Diversity of algal endosymbionts (zooxanthellae) in octocorals: the roles of geography and host relationships. Mol Ecol 14:2403-2417

Visram S, Douglas A (2006) Molecular diversity of symbiotic algae (zooxanthellae) in scleractinian corals of Kenya. Coral Reefs 25:172-176

Warner ME, LaJeunesse TC, Robison JD, Thur RM (2006) The ecological distribution and comparative photobiology of symbiotic dinoflagellates from reef corals in Belize: potential implications for coral bleaching. Limnol Oceanogr 51: $1887-1897$ 